\title{
Hydrogel Fibre: Future Material of Interest for Biomedical Applications
}

\author{
A. K. M. Ayatullah Hosne Asif*, Mahbubur Rahman, Priti Sarker, Md. Zayedul Hasan, \\ Debasree Paul \\ Department of Textile Engineering, Mawlana Bhashani Science and Technology University, Tangail, Bangladesh \\ Email: *ayatasif.mbstu@gmail.com
}

How to cite this paper: Ayatullah Hosne Asif, A.K.M., Rahman, M., Sarker, P., Hasan, Md.Z. and Paul, D. (2019) Hydrogel Fibre: Future Material of Interest for Biomedical Applications. Journal of Textile Science and Technology, 5, 92-107. https://doi.org/10.4236/jtst.2019.54009

Received: August 13, 2019

Accepted: September 22, 2019

Published: September 25, 2019

Copyright $\odot 2019$ by author(s) and Scientific Research Publishing Inc. This work is licensed under the Creative Commons Attribution International License (CC BY 4.0).

http://creativecommons.org/licenses/by/4.0/

\begin{abstract}
Exploration on hydrogel fibres concerning about smart based application in the medical sector has stimulated great interests for the last couple of years due to its wide range of purposes that include actuators, artificial adhesives, transplantable tissue organs, cell scaffolds, cell therapeutics, wound healing, cartilage or bone regeneration. Nevertheless, recently hydrogel fibre based biomaterials have drawn great concentration for use in a wide variety of biomedical applications like the sustained release of drugs. This is due to the fact that, hydrogel fibers are biocompatible and their similarity about physical properties is in relation with natural tissue. This review article prescribes about the application of hydrogels with diversified prospects in tissue engineering, wound care dressings, soft tissue recovery and plastic surgery. As the products of hydrogels are composed with a group of polymeric materials, the hydrophilic network structure makes them competent for holding an immense quantity of water in their three-dimensional polymer network structure. A wide-ranging application of these products in modern industrial and environmental areas has already taken into account to be of prime importance. Inevitably, natural hydrogels right is now gradually replaced by synthetic types due to their larger amount of water absorption capacity, durability alongside with wide ranges of raw chemical resources.
\end{abstract}

\section{Keywords}

Hydrogel, Tissue Engineering, Wound Dressing, Soft Tissue Recovery, Plastic Surgery

\section{Introduction}

Hydrogels are hydrophilic in nature with macromolecular groups, produced by chemical or physical crosslinking of soluble polymers. Because of their strange 
properties of hydrogels for example, highly responsive to physiological environments, hydrophilic in nature, soft tissue-like water content and adequate flexibility, make them excellent aspirants for biomedical based applications, that's why Hydrogels are called materials of the future and gels with hydrophilic nature referred to as hydrogels are networks of polymer chains that are sometimes found as Hydrogels in which water is used as the dispersal medium [1]. Hydrogels can easily swell and de-swell water in a reversible direction, showing specific environmental stimuli responsive for example $\mathrm{pH}$, temperature and ionic potency. For that reason, smart physiological response of hydrogels toward changes of physiological variable suggests their use in various biomedical applications [2]. Perception of hydrogels has been established at the very beginning, as cross-linked 2-hydroxyethyl methacrylate (HEMA) hydrogels have been applied in numerous biomedical applications like carrier of drugs, sutures with absorbable capability, osteoporosis and as neoplasm because of their hydrophilic characters [3].

At that point, it has been studied about calcium-alginate microcapsules for cell engineering application [5] and then, some researchers have constructed synthetic hydrogels (Figure 1) composed of natural polymer such as collagen to attain novel dressing substances, showing optimal conditions for healing of burns and wound dressing [6]. It is needless to say that, polymeric hydrogels have great interests for biomaterial scientists for many years. Application of nanotechnology in modern textile materials has created new dimension in textile based biomaterials processing [7]. Millions of people are exposed to burns by hot water, gas flames, accidents and boiling oil. These accidents can cause major disabilities or even sometimes death every year. Especially in adults, and over-aged people dermis regeneration cannot occur spontaneously again. As autologous skin has limited ease of use and is associated with additional scarring, traditional approach for a substantial loss of dermis cannot meet the requirements, and dressing materials became inevitable for skin tissue or healing

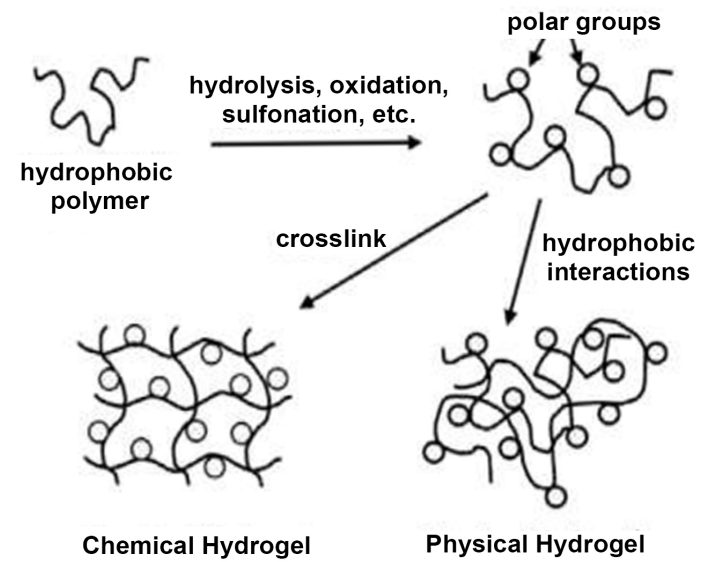

Figure 1. Physical and chemical hydrogels concept, on the left of the figure it represents about the chemical crosslinking network structure is observed and the right side represent about physical cross-linking [4]. 
[8]. Before the time of 1960s, wound dressing materials have been regarded to be only passive materials that have a minimal role in the healing process. A researcher also has established the first generation of wound dressing polymeric materials and presented optimal environments for wound healings [9].

Such kind of awareness transformed the approaches to wound dressing and surfaced the way for the development of wound dressing from the passive to active material and functionalized ones. The desirable wound dressing materials should fulfill the following conditions: (a) maintain a local moist environment, protect the wound from side-infection, absorb the wound fluids and exudates, minimize the wound surface necrosis, (e) prevent the wound dryness, (f) stimulate the growth rate and be elastic, non-toxic, non-antigenic, biocompatible and biodegradable dressing materials [10] [11] [12].

\section{Classification of Hydrogels with Different Approaches}

As mentioned before, hydrogels are three dimensional crosslinked hydrophilic polymer networks capable of swelling or de-swelling reversibly in water and holding large volume of liquid in swollen state [13] [14]. Hydrogels can also be designated with controllable responses such as shrink or expand with changes in external environmental conditions [15] [16]. Hydrogels can execute theatrical volume transition in response to a large variety of physical and chemical stimuli, where the physical stimuli include temperature, electric field or magnetic field, light, pressure, sound as well, while the chemical stimuli include $\mathrm{pH}$, composition of solvent, ionic strength between molecular species illustrated in Figure 2.

The classification of Hydrogels is based on natural and synthetic origins [17] [18]. Classification of hydrogels according to composition of polymer: method of preparation directs to structure of different classes of hydrogels. The classification is listed below [19]:

- The homopolymeric hydrogels are referred to polymer network derived from a single species of monomer, which is a basic structural unit comprising of any polymer network [20]. The cross-linked gaunt structure of Homopolymers depends on nature of the monomer and polymerization technique.

- Another one Copolymeric hydrogels those are encompassed by two or more different monomer kinds having one hydrophilic component, arranged in an arbitrary, block or alternating configuration along the chain of the polymer network [21].

- On the other hand, multipolymer Interpenetrating polymeric hydrogel (IPN) is another type of hydrogels, comprised with two independent cross-linked synthetic and natural polymer components, enclosed in a network form [22]. According to structure, in semi-IPN hydrogel, one component is a cross-linked polymer and other component structure is non cross linked polymer [23].

Technically the amount of swelling or de-swelling (preparation of high swelling hydrogel illustrated in Figure 3 ) in response to the changes in the outdoor environment of the hydrogel might be so severe that the phenomenon is 


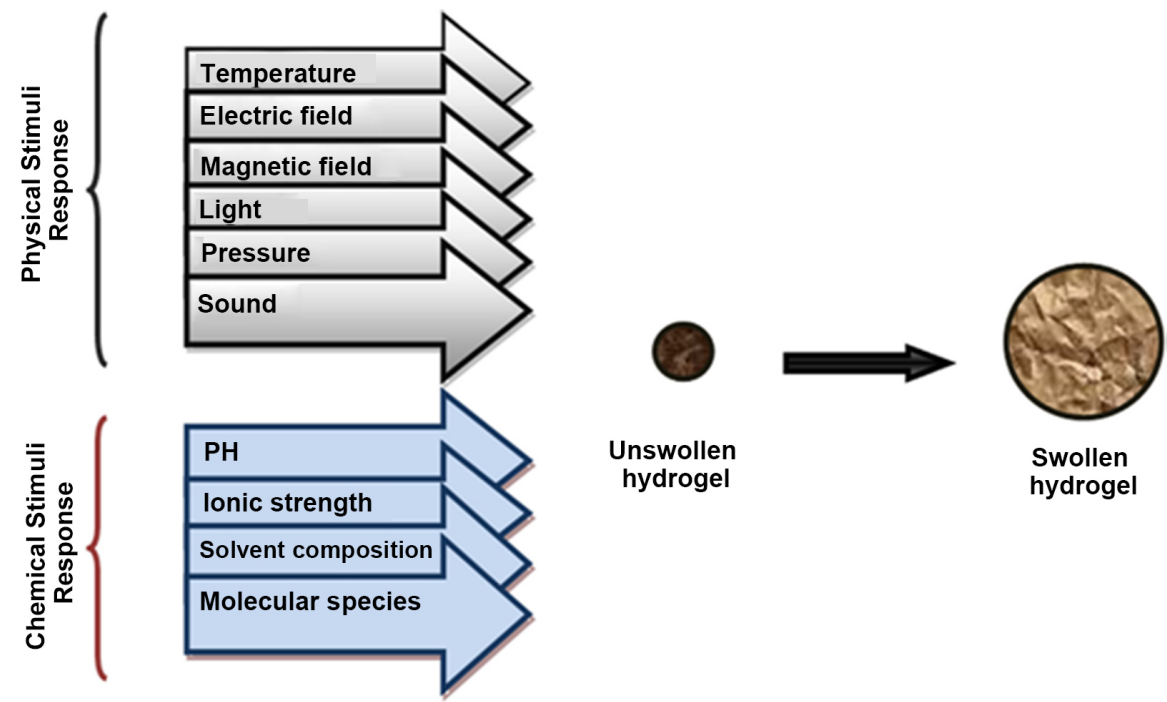

Figure 2. Physical and chemical stimuli responsive swelling hydrogel [19].

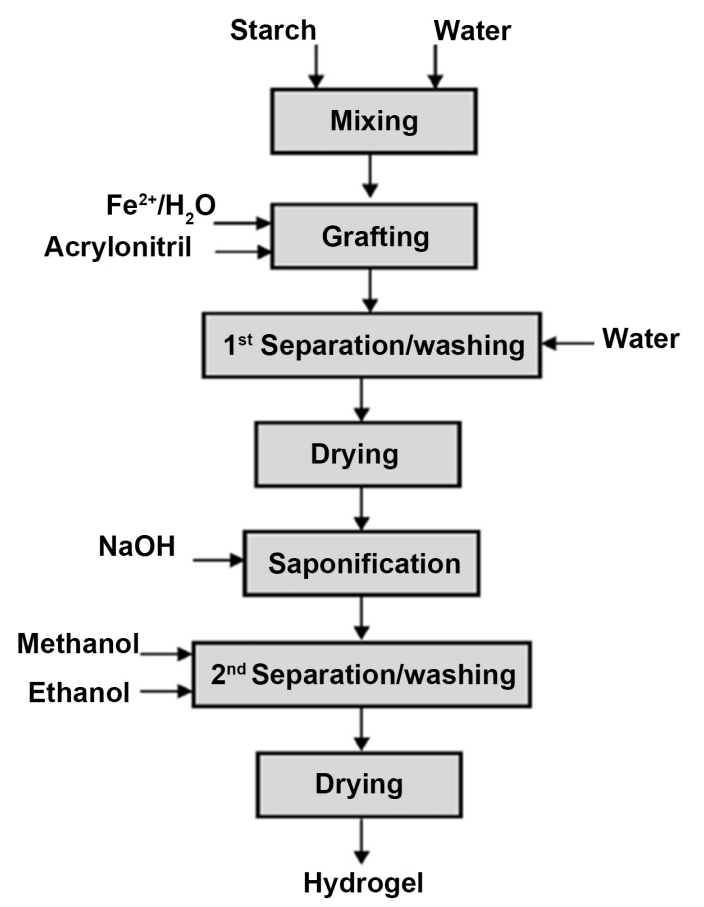

Figure 3. Representation about block diagram of preparation about high swelling hydrogel [24].

sometimes referred to as volume collapse or phase transition [24]. Synthetic hydrogels have been emerged as a ground for wide-ranging research for the past four decades and it still remains at large with active area of research today.

\section{$>$ Classification based on configuration}

The classification of hydrogels depends on their physical structure and chemical composition classified as follows:

a) Amorphous (non-crystalline).

b) Semicrystalline: A complex mixture of amorphous and crystalline phases. 
c) Crystalline.

Classification based on physical appearance

Hydrogels appearance can also be described as matrix, film or microsphere depends on the technique of polymerization involved in the preparation process.

PVA is one of the most common and the oldest synthetic polymer hydrogels because of its good biocompatibility has been applied in different advanced biomedical applications like wound dressings, wound care management, drug delivery systems, artificial organs manufacture and contact lenses [25] [26] [27]. But, PVA hydrogel have insufficient elasticity, stiff membrane structure with very limited hydrophilicity characteristics which confine its use alone as a wound dressing polymeric material. Among the different types of hydrogels described in various literatures, preparation of hydrogels using PVA blended with polysaccharides and some other synthetic polymers are attractive because of the great quantity of such polymers, easy for chemical modification and most of the cases about its good biocompatibility [28] [29].

Synthesis of hydrogels can be done by different classical chemical ways. Among them, one-step procedures like polymerization and parallel cross-linking of multifunctional monomer with multiple step procedures involving synthesis of polymer molecules synthesis operation having reactive groups and their subsequent cross-linking, incorporation with reacting polymers with suitable cross-linking agents [30].

Additionally, the upgradation of functional monomers along with macromeres broadens their applicability. Traditionally hydrogels used as agricultural water absorbents were comprised of biopolymers through grafting of hydrophilic monomers onto starch and other polysaccharides [31] [32]. Hygienic applications of Hydrogel products are mainly relied on acrylic acid and its salts. Acrylamide is referred to as main component employed for preparation of agricultural hydrogel products.

\section{Concept of Hydrogels as Wound Dressings}

In view of the fact that early eighties fundamental properties of membranes as wound dressings to sustain the skin healing and to protect the skin defect zone from infection, have been investigated and applied in the clinical sectors [33]. The mechanism of hydrogels as wound dressings can be described as follows. Hydrogels can absorb and preserve the wound exudates, which promote fibroblast proliferation and keratinocyte migration. The last two processes are very necessary for complete epithelialization and healing of the wound [34]. The tight mesh structure of hydrogels structure protects the wound from infection and prevents microorganism and bacteria to reach the wound area [35]. Nevertheless, hydrogels structure allows transporting bioactive molecules such as antibiotics, and pharmaceuticals to wound centre. Such molecules can be entrapped into hydrogel networks during gelling process, while these molecules can be exchanged with absorbing the wound exudates during the sustainable release 
process after contacting hydrogels with the wound surface. The significant amount of water content in hydrogels provides the necessary flexibility and elasticity to acclimatize wounds in different body sites.

Recently, preparation and fabrication of patterned materials in almost random shapes and dimensions; direct-write assembly has gained enormous interest [36]. Chitosan derivatives have the capability to soluble in acidic, medium and basic conditions, were found better than chitosan itself, due to the antibacterial activity of chitosan was noticed only in acidic physiological conations and inadequate homogeneity between pure chitosan and PVA (Figure 4). The direct-write assembly has created opportunity for many monomers precursor to be patterned for structural hydrogels which can be a good initiative for medical textiles [37]. According to this approach, the spacing, shapes and dimensions of the patterned features can be well controlled over a wide scales range from sub-micrometers to micrometers. The direct-write assembly expands the opportunities for integrating of structural hydrogels with other complex systems, which enables the intelligent chemical actuators to be designed [38]. Unlike prior methods, direct-writing assembly is programmatic fabrication technology which especially applicable to design hierarchical hydrogel scaffolds, serving as potential suitability for tissue engineering applications [39] [40]. Direct writing and actuation of three-dimensionally patterned hydrogel pads are also used for micropillar supports [41].

Technically wound healing is the pledge of a brand new innovation to heal (Figure 5) broken skin tissue with high biocompatible and bioactive materials. Skin burned, diabetic ulceration and sophisticated issues etc. those state of the art technologies are now valuable to treat by technical textiles based smart materials [42] [43]. Prosthetic-tissue designed skin square measure been created, sadly they are not ready-to-use; they are valuable and have several desires that don't seem to be continually suitable for patients. Artificial dressings which can be manufactured from artificial materials like, non-biological textile based materials and polymers, don't seem to be found in skin ingredients [44]. Artificial dressing's composition ought to be a harmless, automatically stable, perishable and presents a correct atmosphere for the tissue repair [45]. Recently, there has to be vast demands for compound membrane materials to be applied for wound

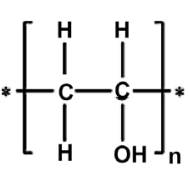

(a)

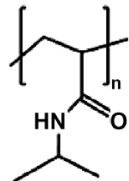

(b)

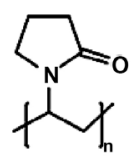

(c)

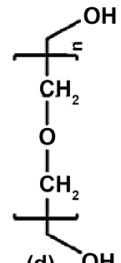

(d) $\mathrm{OH}$<smiles>CCOCCOC(=O)NCCNC(C)=O</smiles>

(e)

Figure 4. Representation of chemical structures of synthetic polymers, employed formerly as hydrogel membranes for wound dressings or skin substitutes, (a) polyvinyl alcohol, (b) poly ( $\mathrm{N}$-isopropylacrylamide), (c) poly ( $\mathrm{N}$-vinylpyrrolidone), (d) polyethylene glycol, (e) polyurethane [35]. 

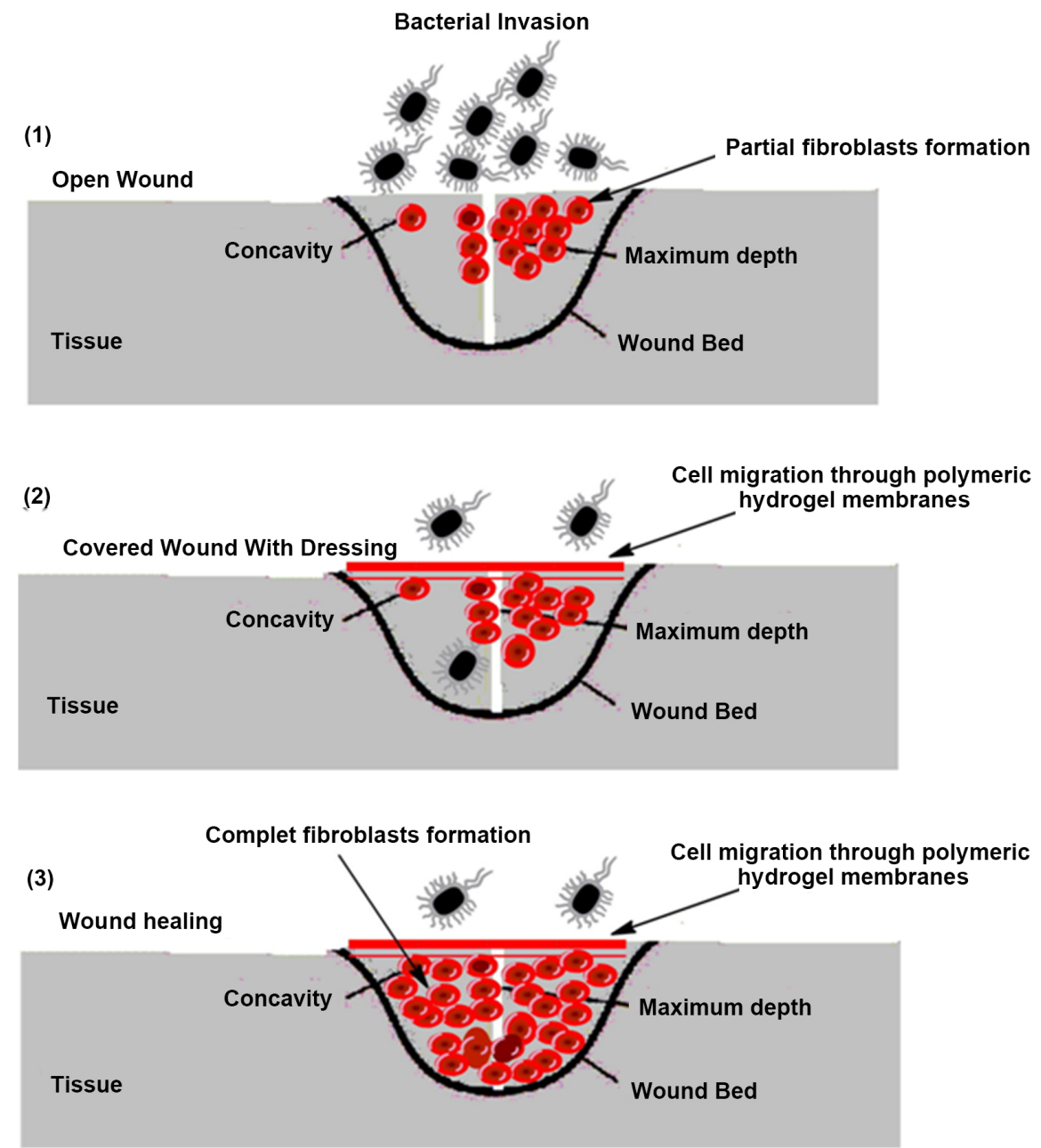

Figure 5. Schematic representation of the hydrogels biomaterials membrane for improvement and acceleration of the wound healing process [49].

dressings [46]. The compound wound dressings used recently in numerous forms like films, foams, fibrous hydrogels, alginates and hydrocolloids based wound dressings in line with the form together with their positives and negatives [47]. While, different compound dressing materials within the world markets and their business names, the optimum use of smart textile products and therefore the utilization proportion within the sector of wounds and burns care are getting popular in medical sector [48].

Like any systhetic textile products, hydrogel fibre based dressings had giant share for wound dressing applications because of their blessings excelled on own disadvantages [50] [51]. At present, polyvinyl acetate which is also known as synthetic fibres is one amongst the foremost and therefore the oldest artificial polymer are utilized as, wound dressings, wound management, drug delivery systems, artificial organs and call lenses. However, polyvinyl acetate based hydrogel fibrous materials have inadequate physical property, stiff membrane and really incomplete hydrophilic characteristics that prohibit its use alone as wound dressing compound membranes [52]. Several processes has been investigated 
with or while not chemicals to assist the skin regeneration, but Hyaluronic-acid and gelatin both of them are promising materials for the aim as a result of their natural presence within human electronic countermeasures of the skin tissues [53].

\section{Hydrogels Application in Soft Tissue Recovery Treatment}

Soft tissue recovery treatment is essential to defeat the restrictions of ordinary treatment to prompt reparative dentinogenesis [54]. By and by, dental specialists must choose the option to evacuate the entire dental mash with an endodontic methodology when a dentin deformity with mash introduction arrives at a basic size bringing about an irreversible mash condition. To beat this confinement, it is viewed as critical to create mash recovery treatment just as explain the components of mash wound recuperating [55]. Mash wound mending and recovery have normal procedures, and consequences of various investigations have demonstrated that mash wound recuperating comprises of beginning enlistments of apoptosis of harmed mash cells, followed by reactionary dentinogenesis by enduring odontoblasts and reparative dentinogenesis by odontoblast-like cells [56]. Reactionary or reparative dentin is shaped toward the remaining dental mash, be that as it may, not in the zone wherein the dentin-mash complex has been lost. To accomplish the recovery of the dentin-pulp complex, enlistment of suitable mash wound recuperating and development of new dentin in dentin deformities are basic, and a couple of studies have announced imperative mash treatments to frame new dentin in imperfections [57].

\section{Hydrogels in Tissue Engineering and Drug Delivery Systems}

As described earlier Hydrogels are three dimensional chemical compound scaffolds utilized in many sustainable applications in technical textiles along with tissue engineering [58]. A wide range of necessary cluster of techniques therefore referred to as in-vivo tissue regeneration (Table 1). During this case, a patient's own cells those are combined with the chemical compound, and command in-vitro till able to be embedded, that's why the hydrogel fibre acts as a natural extra-cellular matrix that afterwards promotes cellproliferation and tissue re-growth. Growth of medical textiles research relating to the pseudo-extra-cellular matrix, comprised of growth factors, metabolites and different materials, brings cells along and controls tissue structure with a view to substitute the natural tissues those were accidentally misplaced or broken [59].

Hydrogel fibres are ideal platforms for restraint totally different biomolecules, either covalently or noncovalently, as beacause hydrogels have high mass and inherent affinity for bio-molecules. Biomolecules unfree inside hydrogels may be designed to own totally different unleash mechanics, like burst or controlled unleash [60]. Another strategy for on-demand unleash of biomolecules applies external stimuli, like ultrasound, light, heat, or magnetic or electrical fields to 
Table 1. Representation of necessary properties and characteristics of hydrogels for tissue engineering application [61].

\begin{tabular}{llll}
\hline $\begin{array}{c}\text { Category of } \\
\text { Hydrogels }\end{array}$ & $\begin{array}{c}\text { Structure of } \\
\text { polymer }\end{array}$ & Compositions & \multicolumn{1}{c}{ Properties } \\
\hline & & & - Closed/open pores \\
& & & Water content and \\
character
\end{tabular}

hydrogels. Such bioresponsive hydrogels may be integrated with electronic devices to watch the discharge of therapeutic molecules at the acceptable time and rate within the body.

According to drug delivery point of view, we tend to intend the total group of procedures, devices and techniques to avoid the issues of ordinary delivery of medicals, such as the burst unharness and fast decay of the results of the drug overtime, particularly for brief half-life prescribed drugs [62]. Hydrogels fibres based smart biomaterials especially, will be really fascinating pledge in reaching a sustained and targeted unharness of prescribed drugs, each increasing the impact of the drug itself and lowering facet effects at a similar time [63]. Researcher pointed out that, silk fibroin from Bombyx mori and from Natherea Mylitta can easily form a 3D scaffold for internal organ tissue engineering. Such kind of innovation stated about metabolic cell response, cardiomyocytes growth and also the range of junction between cells for AntheraeaMylitta fibroin represent terribly kind of like fibronectin ones. Silk fibroin from AM permits connection in treatment efficient attachment of cells while not touching their response to extracellular stimuli.

\section{Functions of Injectable Hydrogels}

Modern medical tests moreover as before animal studies suggested that transplantation of autologous chondrocytes suspended in polymer based alginate gel made encouraging results and prompt that injectable alginate hydrogels might have potential use as bulking agents (Figure 6). Just like stitching in textile based materials; covalently cross-linked alginate hydrogels give a flexible system with potential as associate injectable bulking agent [64]. Shape memory type materials which can also be used in technical textiles show characteristics of those materials expedited the minimally invasive delivery of a bulking construct in a much predefined three-dimensional macroporous form that decreased migration or leak of the fabric from the puncture website and ensured integration with host 


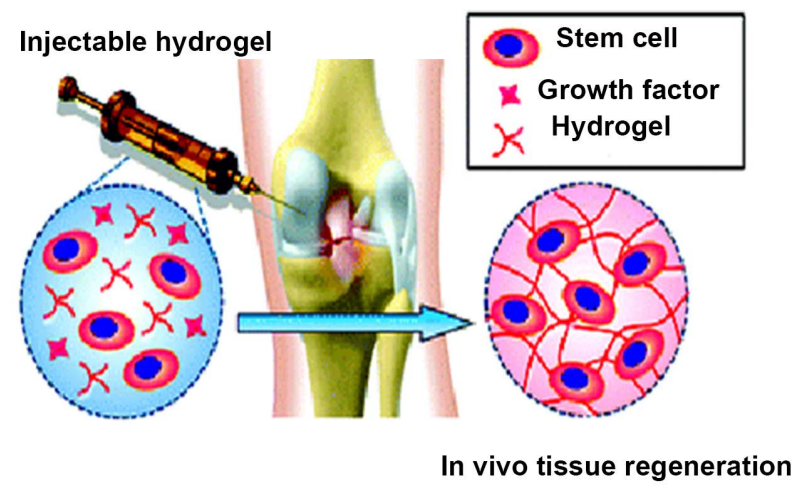

Figure 6. Promising aspects of injectable hydrogels over traditional scaffolds [65].

tissue [65]. The preparation of hydrogels are uncomplicated to organize and might keep dehydrated at temperature, needed no specialized injection instrumentation and might be delivered by one injection. Such hydrogels have the potential to satisfy several needs for associate best epithelial duct or different soft tissue bulking agent.

Due to need and want to attenuate ancient open surgeries and challenges together with the normal endovenous administration of chemotherapeutics for instance, injectable hydrogel-drug system emerges as a robust tool for noninvasive and promising controlled-release of medicine. Such application might conjointly scale back the aid expenses and improve the recovery time for the patients. Such kind of invasive procedures like victimization endoscopes, catheters and needles are developed significantly within the previous few decades [66]. Within the field of tissue engineering and regenerative medication, there's a necessity for advancement over the traditional scaffolds and pre-formed hydrogels [67]. During this situation, injectable hydrogels have gained wider appreciation among the scientists, as they'll be employed in minimally invasive surgical procedures. Injectable gels with their easy handling, complete filling the defect space and smart permeableness have emerged as promising biomaterials in medical applications.

\section{Hydrogels in Plastic Surgery}

In today's scientific research field, apart from textile based fibrous materials; hydrogel fibres are going to take place as good materials for application with the human body because of their extracellular matrix-like (ECM-like) properties [67]. This is the main reason as endeavors are made to initiate hydrogels like new biomaterials for plastic surgery in human body reconstruction.

In moder world, cosmetic surgery is dependent on hydrogels, indeed a pH-Sensitive material P (MAA-co-EGMA) has been developed for unharness of cosmetics medicine like arbutin, adenosine, and niacinamide, well knowing molecules for wrinkle treatment and for skin-whitening. This type of hydrogels modification is permeability responding to the hydrogen ion concentration 
changes: At hydrogen ion concentration of $\mathrm{pH} 4.0$, it holds the prescribed drugs within the matrix, once up-to-date with skin, at hydrogen ion concentration about $\mathrm{pH} 6$ and higher than, the absorption capacity will rise and also the medicine will be delivered [68].

\section{Conclusions}

In this review, we present a summary of applications and technical aspects of the development in hydrogels analysis from basic networks to high-quality materials. Hydrogels area of application is a gift for everyday product although their potential has not been absolutely explored however. These materials have already got a well-established role in eye contact lenses, hygiene product and wound dressing markets; however industrial gel products in tissue engineering and drug delivery area unit are still restricted. Several hydrogel-based drug delivery devices and scaffold shave been designed, studied and in some cases even proprietary, but not several kinds of them have reached the market. A lot of progress is predicted in different areas specifically restricted industrial product with hydrogels in drug delivery and tissue engineering application associated with some extent to their high production prices.

Over the past decades, very important progress has been created in the field of hydrogels as useful biomaterials. Biomedical application of hydrogels was previously hindered by the toxicity of crosslinking agents and limitations of gel formation under physiological conditions. Experimental data in chemical compound chemistry and increased understanding of biological processes resulted within the style of versatile materials and minimally invasive therapies. The hydrogel matrices comprise a large variety of natural and synthetic polymers command along by a spread of physical or chemical crosslinks. With their capability to integrate pharmaceutical agents in their deliquescent crosslinked network, hydrogels emerged as promising materials for controlled drug unleash and tissue engineering. Despite all their useful properties, it is needless to say that still several challenges remain to beat for medical applications.

\section{Compliance with Ethics Requirements}

This article does not contain any studies with human or animal subjects performed by any of the authors.

\section{Acknowledgements}

The authors gratefully acknowledge Research Cell of Mawlana Bhashani Science and Technology University for financial support of this work.

\section{Conflicts of Interest}

The authors have declared no conflict of interest.

\section{References}

[1] Sood, A., Granick, M.S. and Tomaselli, N.L. (2014) Wound Dressings and Compar- 
ative Effectiveness Data. Advances in Wound Care, 3, 511-529. https://doi.org/10.1089/wound.2012.0401

[2] Ahmed, E.M., Aggor, F.S., Awad, A.M. and El-Aref, A.T. (2013) An Innovative Method for Preparation of Nanometal Hydroxide Superabsorbent Hydrogel. Carbohydrate Polymers, 91, 693-698. https://doi.org/10.1016/j.carbpol.2012.08.056

[3] Gibs, I. and Janik, H. (2010) Review: Synthetic Polymer Hydrogels for Biomedical Applications. Chemistry \& Chemical Technology, 4, 297-304.

[4] Hoffman, A.S. (2001) Hydrogels for Biomedical Applications. Advanced Drug Delivery Reviews, 54, 3-12. https://doi.org/10.1016/S0169-409X(01)00239-3

[5] Lim, F. and Sun, A.M. (1980) Microencapsulated Islets as Bioartificial Endocrine Pancreas. Science, 210, 908-910. https://doi.org/10.1126/science.6776628

[6] Yannas, G.P.L., Huang, C., Silver, F.H. and Burke, J.F. (1981) Crosslinked Collagen-Mucopolysaccharide Composite Materials. U.S. Pat. 4,280,954.

[7] Winter, G.D. (1962) Formation of the Scab and the Rate of Epithelization of Superficial Wounds in the Skin of the Young Domestic Pig. Nature, 193, 293-294. https://doi.org/10.1038/193293a0

[8] Asif, A.K.M.A.H. and Hasan, M.Z. (2018) Application of Nanotechnology in Modern Textiles: A Review. International Journal of Current Engineering and Technology, 8, 227-231. https://doi.org/10.14741/ijcet/v.8.2.5

[9] Ana, R.C.P., Rui, L.R. and Nuno, M.N. (2011) Cell and Tissue Engineering-Taking Cues from Nature's Engineering Paradigm for Developing, Growing, and Repairing Tissues. Tissue Engineering Part B: Reviews, 17, 1459-1460.

https://doi.org/10.1089/ten.teb.2010.0704

[10] Jakubiak, J., Sionkowska, A., Linden, L.A. and Rabek, J.F. (2001) Isothermal Photo Differential Scanning Calorimetry. Crosslinking Polymerization of Multifunctional Monomers in Presence of Visible Light Photoinitiator. Journal of Thermal Analysis and Calorimetry, 65, 435-443. https://doi.org/10.1023/A:1012424918321

[11] Kannon, G.A. and Garrett, A.B. (1995) Moist Wound Healing with Occlusive Dressings, a Clinical Review. Dermatologic Surgery, 21, 583-590. https://doi.org/10.1111/j.1524-4725.1995.tb00511.x

[12] Kokabi, M., Sirousazar, M. and Hassan, Z.M. (2007) PVA-Clay Nanocomposite Hydrogels for Wound Dressing. European Polymer Journal, 43, 773-781. https://doi.org/10.1016/j.eurpolymj.2006.11.030

[13] Kenawy, E., Kamoun, E.A., Mohy Eldin, M.S. and El-Meligy, M.A. (2014) Physically Crosslinked Poly(vinyl alcohol)-hydroxyethyl Starch Blend Hydrogel Membranes: Synthesis and Characterization for Biomedical Applications. Arabian Journal of Chemistry, 7, 372-380. https://doi.org/10.1016/j.arabjc.2013.05.026

[14] Zhao, L., Mitomo, H., Zhai, M., Yoshii, F., Nagasawa, N. and Kume, T. (2003) Synthesis of Antibacterial PVA/CM-Chitosan Blend Hydrogels with Electron Beam Irradiation. Carbohydrate Polymers, 53, 439-446. https://doi.org/10.1016/S0144-8617(03)00103-6

[15] Muggli, D.S., Burkoth, A.K. and Anseth, K.S. (1998) Crosslinked Polyanhydrides for Use in Orthopedic Applications: Degradation Behavior and Mechanics. Journal of Biomedical Materials Research, 46, 271-278.

https://doi.org/10.1002/(SICI)1097-4636(199908)46:2<271::AID-JBM17>3.0.CO;2$\underline{\mathrm{X}}$

[16] Yang, X., Liu, Q., Chen, X., Yu, F. and Zhu, Z. (2008) Investigation of PVA/Ws-Chitosan Hydrogels Prepared by Combined Gama-Irradiation and 
Freeze-Thawing. Carbohydrate Polymers, 73, 401-408.

https://doi.org/10.1016/j.carbpol.2007.12.008

[17] Hyon, S.H., Cha, W.I., Ikada, Y., Kita, M., Ogura, Y. and Honda, Y. (1994) Poly(vinyl alcohol) Hydrogels as Soft Contact Lens Material. Journal of Biomaterials Science, Polymer Edition, 5, 397-406. https://doi.org/10.1163/156856294X00103

[18] Coviello, T., Matricardi, P., Marianecci, C. and Alhaique, F. (2007) Polysaccharide Hydrogels for Modified Release Formulations. Journal of Controlled Release, 119, 5-24. https://doi.org/10.1016/j.jconrel.2007.01.004

[19] Enas, M.A. (2015) Hydrogel: Preparation, Characterization and Applications: A Review. Journal of Advanced Research, 6, 105-121. https://doi.org/10.1016/j.jare.2013.07.006

[20] Burkert, S., Schmidt, T., Gohs, U., Dorschner, H. and Karl-Friedrich, A. (2007) Cross-Linking of Poly(N-vinyl pyrrolidone) Films by Electron Beam Irradiation. Radiation Physics and Chemistry, 76, 1324-1328. https://doi.org/10.1016/j.radphyschem.2007.02.024

[21] Wen, Z., Xing, J., Yang, C., Yuying, L. and Jun, F. (2013) Degradable Natural Polymer Hydrogels for Articular Cartilage Tissue Engineering. Journal of Chemical Technology \& Biotechnology, 88, 327-339. https://doi.org/10.1002/jctb.3970

[22] Takashi, L., Hatsumi, T., Makoto, M., Takashi, I., Takehiko, G. and Shuji, S. (2007) Synthesis of Porous Poly(N-isopropylacrylamide) Gel Beads by Sedimentation Polymerization and Their Morphology. Journal of Applied Polymer Science, 104, 842-850. https://doi.org/10.1002/app.25605

[23] Maolin, Z., Jun, L., Min, Y. and Hongfei, H. (2000) The Swelling Behaviour of Radiation Prepared Semi-Interpenetrating Polymer Networks Composed of polyNIPAAm and Hydrophilic Polymers. Radiation Physics and Chemistry, 58, 397-400. https://doi.org/10.1016/S0969-806X(99)00491-0

[24] Hacker, M.C. and Mikos, A.G. (2011) Synthetic Polymers. In: Principles of Regenerative Medicine, 2nd Edition, Academic Press, San Diego, 587-622. https://doi.org/10.1016/B978-0-12-381422-7.10033-1

[25] Shin, J., Braun, V. and Lee, W. (2010) Fast Response Photonic Crystal pH Sensor Based on Templated Photopolymerized Hydrogel Inverse Opal. Sensors and Actuators B: Chemical, 150, 183-190. https://doi.org/10.1016/j.snb.2010.07.018

[26] Park, J.H. and Kim, D. (2001) Preparation and Characterization of Water-Swellable Natural Rubbers. Journal of Applied Polymer Science, 80, 115-121. https://doi.org/10.1002/1097-4628(20010404)80:1<115::AID-APP1079>3.0.CO;2-K

[27] Pourjavadi, A., Harzandi, A.M. and Hosseinzadeh, H. (2004) Modified Carrageenan 3. Synthesis of a Novel Polysaccharide-Based Superabsorbent Hydrogel via Graft Copolymerization of Acrylic Acid onto Kappa-Carrageenan in Air. European Polymer Journal, 40, 1363-1370. https://doi.org/10.1016/j.eurpolymj.2004.02.016

[28] Bullock, A.J., Pickavance, P., Haddow, D.B., Rimmer, S. and MacNeil, S. (2010) Development of Calcium-Chelating Hydrogel for Treatment of Superficial Burns and Scalds. Regenerative Medicine, 5, 55-64. https://doi.org/10.2217/rme.09.67

[29] Kim, T.H., An, D.B., Oh, S.H., Kang, M.K., Song, H.H. and Lee, J.H. (2015) Creating Stiffness Gradient Polyvinyl Alcohol Hydrogel Using a Simple Gradual Freezing-Thawing Method to Investigate Stem Cell Differentiation Behaviors. Biomaterials, 40, 51-60. https://doi.org/10.1016/j.biomaterials.2014.11.017

[30] Gratson, G.M., Xu, M. and Lewis, J.A. (2004) Microperiodic Structures: Direct Writing of Three-Dimensional Webs. Nature, 428, 386. 
https://doi.org/10.1038/428386a

[31] Duoss, E.B., Twardowski, M. and Lewis, J.A. (2007) Sol Gel Inks for Direct-Write Assembly of Functional Oxides. Advanced Materials, 19, 3485-3489. https://doi.org/10.1002/adma.200701372

[32] Barry, R.A., Shepherd, R.F., Hanson, J.N., Nuzzo, R.G., Wiltzius, P. and Lewis, J.A. (2009) Direct-Write Assembly of 3D Hydrogel Scaffolds for Guided Cell Growth. Advanced Materials, 21, 2407-2410. https://doi.org/10.1002/adma.200803702

[33] Zarzar, L.D., Kim, P., Kolle, M., Brinker, C.J., Aizenberg, J. and Kaehr, B. (2011) Direct Writing and Actuation of Three-Dimensionally Patterned Hydrogel Pads on Micropillar Supports. Angewandte Chemie, 123, 9528-9532. https://doi.org/10.1002/ange.201102975

[34] Shuanhong, M., Bo, Y., Xiaowei, P. and Feng, Z. (2016) Structural Hydrogels. Polymer, 98, 516-535. https://doi.org/10.1016/j.polymer.2016.06.053

[35] Lee, S.C., Kwon, I.K. and Park, K. (2013) Hydrogels for Delivery of Bioactive Agents: A Historical Perspective. Advanced Drug Delivery Reviews, 65, 17-20. https://doi.org/10.1016/j.addr.2012.07.015

[36] Kopecek, J. (2007) Hydrogel Biomaterials: A Smart Future? Biomaterials, 28, 5185-5192. https://doi.org/10.1016/j.biomaterials.2007.07.044

[37] Iqbal, M.S., Mamun, M.A.A., Siddiquee, M.A.B. and Asif, A.K.M.A.H. (2016) Effect of Finishing Machine Parameters on Dimensional Stability of Single Lacoste Cotton Knitted Fabric. Advances in Materials, 5, 35-43. https://doi.org/10.11648/j.am.20160505.12

[38] Wichterle, O. and Lìm, D. (1960) Hydrophilic Gels for Biological Use. Nature, 185, 117-118. https://doi.org/10.1038/185117a0

[39] Buwalda, S.J., Boere, K.W., Dijkstra, P.J., Feijen, J. and Vermonden, T. (2014) Hydrogels in a Historical Perspective: From Simple Networks to Smart Materials. Journal of Controlled Release, 190, 254-273. https://doi.org/10.1016/j.jconrel.2014.03.052

[40] Choudhury, N.A., Sampath, S. and Shukla, A.K. (2008) Hydrogel-Polymer Electrolytes for Electrochemical Capacitors: An Overview. Energy \& Environmental Science, 2, 55-67. https://doi.org/10.1039/B811217G

[41] Chirani, N., Yahia, L.H. and Gritsch, L. (2016) History and Applications of Hydrogels. Journal of Biomedical Science, 4, 2. https://doi.org/10.4172/2254-609X.100013

[42] Mamun, M.A.A., Rahman, M., Asif, A.K.M.A.H. and Sarkar, P. (2014) Effect of Dyeing Parameters on Color Strength and Fastness Properties of Cotton Knitted Fabric Dyed with Direct Dyes. International Journal of Current Engineering and Technology, 4, 1068-1072.

[43] Yom-Tov, O., Neufeld, L., Seliktar, D. and Bianco-Peled, H. (2014) A Novel Design of Injectable Porous Hydrogels with in Situ Pore Formation. Acta Biomaterialia, 10, 4236-4246. https://doi.org/10.1016/j.actbio.2014.07.006

[44] Razzaque, A., Saha, J., Asif, A.K.M.A.H. and Rahman, M. (2015) Influence of Pin Spacer on Yarn Quality in a Ring Frame. International Journal of Current Engineering and Technology, 5, 2380-2382.

[45] Abebe, D.G. and Fujiwara, T. (2012) Controlled Thermoresponsive Hydrogels by Stereocomplexed PLA-PEG-PLA Prepared via Hybrid Micelles of Premixed Copolymers with Different PEG Lengths. Biomacromolecules, 13, 1828-1836. https://doi.org/10.1021/bm300325v

[46] Chung, H.J., Lee, Y. and Park, T.G. (2008) Thermo-Sensitive and Biodegradable 
Hydrogels Based on Stereocomplexed Pluronic Multi-Block Copolymers for Controlled Protein Delivery. Journal of Controlled Release, 127, 22-30. https://doi.org/10.1016/j.jconrel.2007.12.008

[47] Bae, M.S., Ohe, J.Y., Lee, J.B., Heo, D.N. and Byun, W. (2014) Photocured Hyaluronic Acid-Based Hydrogels Containing Growth and Differentiation Factor 5 (GDF-5) for Bone Tissue Regeneration. Bone, 59, 189-198. https://doi.org/10.1016/j.bone.2013.11.019

[48] Ueno, Y., Kitamura, C., Terashita, M. and Nishihara, T. (2006) Re-Oxygenation Improves Hypoxia-Induced Pulp Cell Arrest. Journal of Dental Research, 85, 824-828. https://doi.org/10.1177/154405910608500909

[49] Elbadawy, A.K., El-Refaie, S.K. and Xin, C. (2017) A Review on Polymeric Hydrogel Membranes for Wound Dressing Applications: PVA-Based Hydrogel Dressings. Journal of Advanced Research, 8, 217-233. https://doi.org/10.1016/j.jare.2017.01.005

[50] Kawagishi, E., Nakakura, O.K., Nomura, S. and Ohshima, H. (2006) Pulpal Responses to Cavity Preparation in Aged Rat Molars. Cell and Tissue Research, 326, 111-122. https://doi.org/10.1007/s00441-006-0230-4

[51] Asif, A.K.M.A.H. (2017) An Overview of Sustainability on Apparel Manufacturing Industry in Bangladesh. Science Journal of Energy Engineering, 5, 1-12. https://doi.org/10.11648/j.sjee.20170501.11

[52] Rokonuzzaman, M., Mamun, M.A.A. and Asif, A.K.M.A.H. (2017) Effect of Heat Setting Conditions on the Quality of Yarn. Frontiers in Science, 7, 46-49.

[53] Qiao, Y., Huang, Y., Qiu, C., Yue, X. and Deng, L. (2010) The Use of PEGylated Poly[2-(N,N-dimethylamino) ethyl methacrylate] as a Mucosal DNA Delivery Vector and the Activation of Innate Immunity and Improvement of HIV-1-Specific Immune Responses. Biomaterials, 31, 115-123. https://doi.org/10.1016/j.biomaterials.2009.09.032

[54] Greenland, J.R. and Letvin, N.L. (2007) Chemical Adjuvants for Plasmid DNA Vaccines. Vaccine, 25, 3731-3741. https://doi.org/10.1016/j.vaccine.2007.01.120

[55] Hadi, M. and Viraraghavan, T. (1999) Removal of Oil from Water by Bentonite Organo-Clay. Hazardous \& Industrial Wastes-Proceedings of the Mid-Atlantic Industrial \& Hazardous Waste, 187-196.

[56] Qiu, Z., Zhang, Y. and Fang, Y. (1995) Removal of Oil from Concentrated Wastewater by Attapulgite and Coagulant. Water Quality Research Journal, 30, 89-100. https://doi.org/10.2166/wqrj.1995.013

[57] Sokker, H.H., El-Sawy, N.M., Hassan, M.A. and El-Anadouli, B.E. (2011) Adsorption of Crude Oil from Aqueous Solution by Hydrogel of Chitosan Based Polyacrylamide Prepared by Radiation Induced Graft Polymerization. Journal of Hazardous Materials, 190, 359-365. https://doi.org/10.1016/j.jhazmat.2011.03.055

[58] Heginbothom, M., Fitzgerald, T.C. and Wade, W.G. (1990) Comparison of Solid Media for Cultivation of Anaerobes. Journal of Clinical Pathology, 43, 253-256. https://doi.org/10.1136/jcp.43.3.253

[59] Chirani, N.A., Dembahri, Z., Tokarski, C., Rolando, C. and Benmouna, M. (2011) Newly Designed Polyacrylamide/Dextran Gels for Electrophoresis Protein Separation: Synthesis and Characterization. Polymer International, 60, 1024-1029. https://doi.org/10.1002/pi.3035

[60] Anseth, K.S., Bowman, C.N. and Brannon-Peppas, L. (1996) Mechanical Properties of Hydrogels and Their Experimental Determination. Biomaterials, 17, 1647-1657. https://doi.org/10.1016/0142-9612(96)87644-7 
[61] Myung, D., Waters, D., Wiseman, M., Duhamel, P.E. and Noolandi, J. (2008) Progress in the Development of Interpenetrating Polymer Network Hydrogels. Polymers for Advanced Technologies, 19, 647-657. https://doi.org/10.1002/pat.1134

[62] Siddiquee, M.A.B., Asif, A.K.M.A.H., Khan, R.H., Anwar, M.T., Islam, M.S. and Noushin, N. (2016) Study on the Effect of Dyeing and Finishing Parameters on Cotton Knitted Two Thread Fleece Fabric and 1x1 Rib Fabric. Science Research, 4, 7-10. https://doi.org/10.11648/j.sr.20160401.12

[63] Rahman, M., Asif, A.K.M.A.H., Siddiquee, M.A.B. and Rokonuzzaman, M. (2014) Effect of Shade Percentage on Various Properties of Cotton Knitted Fabric Dyed with Reactive Dyes. International Journal of Research in Engineering and Technology, 3, 339-343. https://doi.org/10.15623/ijret.2014.0302061

[64] Kun, L., Ki, H.B. and Motoichi, K. (2019) Recent Advances in the Design of Injectable Hydrogels for Stem Cell-Based Therapy. Journal of Materials Chemistry B, 7, 3775-3791. https://doi.org/10.1039/C9TB00485H

[65] Kim, S.J., Yoon, S.G. and Kim, S.I. (2004) Synthesis and Characterization of Interpenetration Polymer Network Hydrogels Composed of Alginate and Poly(diallyldimethylammonium chloride). Journal of Applied Polymer Science, 91, 3705-3709. https://doi.org/10.1002/app.13615

[66] Wang, J.J. and Liu, F. (2013) Enhanced Adsorption of Heavy Metal Ions onto Simultaneous Interpenetrating Polymer Network Hydrogels Synthesized by UV Irradiation. Polymer Bulletin, 70, 1415-1430. https://doi.org/10.1007/s00289-013-0934-z

[67] Pawar, R.S., Chaurasiya, P.K., Rajak, H., Singour, P.K., Toppo, F.A. and Jain, A. (2013) Wound Healing Activity of Sida cordifolia Linn. in Rats. Indian Journal of Pharmacology, 45, 474-478. https://doi.org/10.4103/0253-7613.117759

[68] Hoare, T.R. and Kohane, D.S. (2008) Hydrogels in Drug Delivery: Progress and Challenges. Polymer, 49, 1993-2007. https://doi.org/10.1016/j.polymer.2008.01.027 